\title{
Regulation of Tumor Progression by Extracellular Galectin-3
}

\author{
Pratima Nangia-Makker • Vitaly Balan • Avraham Raz
}

Received: 31 December 2007 / Accepted: 14 January 2008 / Published online: 20 February 2008

(C) Springer Science + Business Media B.V. 2008

\begin{abstract}
The relationship between a tumor cell and its microenvironment is bi-directional. The proteins expressed by the tumor cells alter the signatures on the seemingly normal stromal cells within the microenvironment, while the tumor cell signatures reflect the changes that occur as these cells interact with the host microenvironment. Galectin-3 is a carbohydrate-binding protein that is overexpressed in a variety of tumors and immune cells in response to various stimuli. Ever since its discovery, it has been associated with cell and extracellular matrix interactions. However, in the last decade, an extensive accumulation of data has changed the perspective of this multifunctional protein. The unique structure of this protein, consisting of a carbohydrate-binding domain and a matrix metalloproteinase cleavable domain, enables it to interact with a plethora of ligands in a carbohydratedependent or independent manner. It is now becoming evident that galectin-3 is involved with a variety of extracellular functions like cell adhesion, migration, invasion, angiogenesis, immune functions, apoptosis and endocytosis. Galectin-3 is a substrate for matrix metalloproteinases and its cleavage plays an important role in tumor progression and can be used as a surrogate diagnostic marker for in vivo MMP activity.
\end{abstract}

Keywords Galectin-3 · Extracellular - Tumor progression . Carbohydrate-recognition domain · Collagen-like domain

P. Nangia-Makker $\cdot$ V. Balan $\cdot$ A. Raz $(\bowtie)$

Karmanos Cancer Institute, Wayne State University,

110 E. Warren Avenue,

Detroit, MI 48201, USA

e-mail: raza@karmanos.org

\section{Introduction}

During cancer growth, tumor cells interact with the surrounding environment. Mounting evidence now suggests that the cancer cell and its microenvironment profoundly influence each other and that a dynamic interaction occurs between the two. The tumor microenvironment consists of a variety of cell types, parts of the blood and lymphatic systems and is rich in growth factors and enzymes, which provide a readily available source of growth-promoting signals to tumor cells. The influence between the environment and tumor cells is bi-directional. The microenvironment permits the tumor cells to grow and spread, while giving access to therapeutic agents and/or developing resistance to cancer treatments. Non-cancerous adjoining cells or the stromal cells in the microenvironment often take on atypical characteristics and exert a profound influence on a cancer cell's ability to develop into a tumor. It is not yet established whether these neighboring cells lose their tumor suppressing properties or whether they acquire growth promoting properties or both. Expression and release of many proteins from inflammatory and cancer cells in the tumor microenvironment activates the signaling cascades that regulate processes like tumor cell migration, invasion, angiogenesis, apoptosis and metastasis. Certain families of cell adhesion proteins like integrins, cadherins and lectins have received extensive attention in the last few decades. Lectins are non-enzymatic proteins present in plants and animals, which specifically bind to carbohydrate structures and play an important role in cell recognition.

In this review we have focused on a member of the lectin family, galectin-3, which binds and interacts with a number of glyco-conjugates in the intra- and extra-cellular environment and regulates many biological functions and signaling pathways in normal and cancer cells. 


\section{Structure of Galectin-3 and Its Cellular and Extracellular Distribution in Normal and Cancer Cells}

Galectin-3 is a $\sim 31 \mathrm{kDa}$ unique chimeric gene product belonging to the family of non-integrin $\beta$-galactoside binding lectins with related amino acid sequences. Galectin-3 is ubiquitously expressed in human adults, but the level of expression varies by origin of the tissue. It is widely expressed in epithelial and immune cells, such as gastric mucosa, colon mucosa, mammary epithelium, prostate epithelium, monocytes, and macrophages [reviewed in 1]. During the first trimester of human embryogenesis, the expression of galectin-3 is restricted to epithelia, such as the skin, epithelial lining of the digestive and respiratory tract, urothelium and excretory tubes of the kidney, the myocardial cells, the peripheral and preossifying hypertrophic chondrocytes, as well as in notochord and the liver $[2,3]$.

Galectin-3 consists of three structural domains, each associated with at least one specific function: (a) a $\mathrm{NH} 2$ terminal domain containing a serine phosphorylation site, which is important in regulating its cellular signaling; (b) a collagen- $\alpha$-like sequence cleavable by matrix metalloproteinases; and (c) a $\mathrm{COOH}$ terminal containing a single carbohydrate-recognition domain (CRD) and the NWGR anti-death motif. Galectin-3 is mainly a cytosolic protein, but can easily traverse the intracellular and plasma membranes to translocate into the nucleus, mitochondria or get externalized. This suggests that galectin-3 is a shuttling protein and may have multiple functions accordingly [4-6]. Galectin-3 is expressed in a variety of tumors. The intensity of expression and localization depends on tumor progression, invasiveness and metastatic potential. Galectin-3 translocates to the perinuclear membrane in breast cancer cells following a variety of apoptotic stimuli such as cisplatin, staurosporine, or serum withdrawal [7-9]. In human breast carcinoma, nuclear staining of galectin-3 was correlated to the lobular type of invasive carcinoma, while tumor stromal expression to high-grade malignancy [10, 11]. Sanjuan et al. [12] reported an increased cytoplasmic expression of galectin-3 in more advanced stages of colorectal cancer. Over-expression of galectin-3 in the cytoplasm in human prostate cancer can promote its antiapoptotic activity as well as increase cell proliferation, tumor growth, invasion, and angiogenesis while galectin-3 expression in the nucleus decreases cell proliferation [13]. The enhanced expression of galectin-3 in the cytoplasm was associated with a decreased disease-free survival of tongue cancer patients [14].

Galectin-3 lacks the classical secretion signal sequence and does not pass through the standard ER/Golgi pathway [15]. Still it can be transported into the extracellular milieu via a non-classical pathway [16]. There is ample evidence to confirm its presence on the cell surface, in the conditioned medium of some cell lines, in the extracellular matrix and in the biological fluids and sera. It has been shown that the NH2 terminal domain of galectin-3 is critical for its secretion and is the driving force that localizes it in the secretory vesicles [17]. Lukyanov et al. [18] demonstrated the ability of galectin- 3 to cross the lipid bilayer of large unilamellar vesicles, suggesting that the lectin has yet an unknown novel sequence that enables it to traverse lipid membranes. Cells differ widely in their capacity to secrete galectin-3. While J774.2 macrophage cells secrete $30-45 \%$ of their galectin pool [19], BHK and MDCK cells export 10-15\% [20, 21] and WEHI-3 mouse macrophages secrete a very small percentage of galectin-3 in the conditioned medium [19]. The exact mechanism of galectin-3 secretion is not yet known. Hugh's group proposed a vesicular release of galectin-3 from the cells [20-23], while another pathway implicating galectin-3 to be a component of the exosomes secreted by dendritic cells was proposed by Thery et al. [24]. Recently, it was demonstrated that galectin-3 is secreted and taken up by the cells using a mechano-transduction mechanism [25]. Detached and spherical cells secrete galectin-3 in a constitutive manner while attached and spreading cells take up galectin-3 from the conditioned medium [25]. This group also suggested that fetuin could act as a trigger for the release of galectin-3 from the cells [26]. Once the vesicles containing galectin-3 are exported outside of the cell, galectin-3 is released into the extracellular matrix, where it can interact with a myriad of partners regulating a number of biological functions. The focus of this review is on the biological functions regulated by extracellular galectin-3 and their implication in cancer progression.

\section{Role of Galectin-3 in Cell-Matrix and Cell-Cell Interactions}

The biological activities of galectin-3 in the extra-cellular compartment mainly involve its interactions with various $\beta$-galactoside containing glycans via its carbohydrate recognition domain (CRD). The interaction of galectin-3 or its CRD with carbohydrate ligands is accompanied by a conformational change [27] and rearrangement of the backbone loops near the binding site [28]. Mazurek et al. [29] demonstrated that the phosphorylation at $\operatorname{Ser}^{6}$ of galectin-3 strongly affects its sugar binding affinity, thus it was proposed to be an "on/off" switch of its downstream biological effects. There are numerous structurally and functionally diverse biological ligands of galectin-3, some of which have been well characterized. Exogenously added galectin-3 promoted the adhesion of polymorphonuclear neutrophils (PMN) to laminin-coated plastic in a carbohy- 
drate-dependent manner, moreover, the presence of the amino-terminal region was important for this adhesion [30]. Galectin-3 was shown to bind to glycosylated components of extracellular matrix like laminin [30,31] and fibronectin [32], as well as hensin [33], elastin [34], collagen IV [34] and tenascin-C and $-\mathrm{R}$ [35]. Galectin-3 was essential for rapid adhesion of galectin-3 expressing BT-549 cells to laminin and collagen, but not to fibronectin [36]. Likewise, galectin-3 transfected Evsa-T human breast cancer cells showed a higher adhesion to laminin, fibronectin and vitronectin-coated plastic compared to the parental cells [37]. Similarly, normal fibroblasts engineered to overexpress galectin- 3 have also been shown to reorganize the actin microfilaments in order to spread [38]. The interactions of galectin-3 with lysosomal membrane glycoproteins Lamp-1 and -2 [39], carcinoembryonic antigen [40] and colon cancer mucin [41] were suggested to be involved in adhesion of cancer cells to extra-cellular matrix. In addition, another class of cell adhesion proteins, integrins ( $\alpha 1 \beta 1$ [34], and $\alpha \mathrm{M} \beta 1$ [39]) were shown to be galectin-3 receptors. Galectin-3 transfected cells showed higher levels of $\alpha 6 \beta 1$ integrin [42]. Regulation of $\alpha 4 \beta 7$ integrin expression by galectin-3 was also reported [37]. Galectin3 was involved in the endocytosis of $\beta 1$ integrins (CD29) from the cell surface to intracellular vesicles via the caveolae pathway [43]. Negative modulation of cell adhesion to ECM proteins by galectin-3 has also been well documented. For instance, high levels of galectin-3 on the cell surface down-regulated cellular adhesion to ECM proteins in a dose dependent manner. This effect was abrogated in the presence of lactose [36]. The binding of galectin-3 expressing SCM 153 human breast cancer cells, A2058 and A375 melanoma cells to laminin was independent of lactose or anti-gal-3 mAb inhibition [31, 44].

Although galectin-3 possesses only one CRD, it exhibits bi-/multivalent binding properties [45, 46]. Both the carbohydrate recognition and $\mathrm{N}$-terminal domains were shown to be involved in formation of galectin-3 multimers [47, 48]. Dimer or multimer formation of galectin-3 is implicated in aggregation of tumor cells in the circulation during metastasis by mediating homotypic cell adhesion via bridging with branched, soluble complementary glycoconjugates [49]. This spontaneous carcinoma cell homotypic aggregation was shown to be mediated, in part, by the interactions between cell surface Thomsen-Friedenreich glycoantigen (TFAg) and galectin-3 [50, 51]. Grassadonia et al. [52] on the other hand, demonstrated that the association of galectin-3 with $90 \mathrm{~K} /$ Mac-2BP in the extracellular matrix was responsible for the homotypic aggregation. Galectin-3 mediates CD98 dimerization by binding to the heavy chain of CD98, present on human and mouse monocytes/macrophages and on activated $\mathrm{T}$ cells, which in turn can promote integrin activation [39, 53]. Galectin-3 is also involved with heterotypic cell-cell interactions. It promotes the adhesion of breast cancer cells MDA-MB-435 to HUVEC [54] and endothelium, which was inhibited by TFAg specific peptide [51]. Similarly, galectin-3 expressed on endothelial cells could interact with ligands on the cell surface of carcinoma cells. For example, binding of EC to galectin-3 null PC3 human prostate carcinoma cells could be inhibited by anti-gal-3 mAbs [55]. Similarly, antigalectin-3 mAb inhibited the MDA-MB-435 cells rolling and adhesion to HUVEC under flow conditions [56]. Galectin-3 expression was markedly enhanced in the plasma membrane of EC after PMN adhesion, suggesting its importance in PMN/EC interactions [57]. Krishnan et al. [58] demonstrated that galectin- 3 constitutively expressed on the lung vascular EC surfaces plays a key role in the adhesion of circulating B16F10 murine melanoma cells to lungs. A significant role of galectin-3 in cell-cell adhesion was also demonstrated by specific inhibitors. Modified citrus pectin, a carbohydrate ligand for galectin-3 inhibited galectin-3 mediated homotypic as well as heterotypic aggregation [59,60]. In addition, two small peptides that specifically bind to galectin-3 CRD, interfered with rolling and stable adhesion of human breast carcinoma cells to bone marrow EC and dramatically reduced homotypic cell aggregation [61].

\section{Role of Galectin-3 in Cell Migration, Chemotaxis and Cell Activation}

There is enough experimental evidence to suggest that galectin-3 can trigger signal transduction cascades by crosslinking with the glycan parts of the surface glycoconjugates, which in turn activate numerous biochemical pathways in the cells, leading to the activation of various cell types. For example, galectin-3 was shown to induce endothelial cell morphogenesis and angiogenesis in vitro and in vivo [54]. In addition, NG2, a transmembrane chondroitin sulfate proteoglycan, was shown to mediate the induction of endothelial cell motility and multicellular network formation in vitro and the stimulation of corneal angiogenesis in vivo by forming the NG2-galectin-3- $\alpha 3 \beta 1$ integrin complex, suggesting a mechanism by which galectin-3 may induce angiogenesis [62]. The extra-cellular galectin-3 also acts as a chemoattractant for monocytes and macrophages, as well as alveolar macrophages [63]. By in vivo and in vitro studies it was shown that higher concentrations of galectin-3 $(1 \mu \mathrm{M})$ are necessary for chemotactic effects, while lower concentrations (10 $100 \mathrm{nM}$ ) induce increased non-directional cell movements (chemokinesis). Chemotactic, but not chemokinetic activity of galectin-3 was mediated by a pertussis toxin sensitive pathway (G-protein-coupled cell surface receptors) [63]. Galectin-3 was involved with the migration of tumor astrocytes and their invasion into the surrounding brain 
parenchyma [64]. In the thymus, galectin-3 was produced by the stroma, and reported as a modulator of thymocyte migration by interfering with cell adhesion and promoting subsequent detachment [65]. Similarly, galectin-3 transfected breast (BT-549) and lung carcinoma (DLKP) cells were more motile and invasive compared to the parental cells $[42,66]$. Over-expression of galectin-3 accompanied by increased cell surface expression of $\alpha 4 \beta 7$ integrins, caused enhanced adhesion to ECM glycoproteins as well as increased invasiveness and spread [37]. At low concentrations galectin-3 stimulated cell spreading and motility in ß 1,6-acetylglucosaminyltransferase V (Mgat5) +/+ tumor cells plated on a fibronectin substrate [67]. Some of the exceptions are decreased motility of HCT-15, LoVo and CoLo 201 human colon cancer cells on a Matrigel coated surface by over-expression of galectin-3 [68], and an increased motility in human glioblastoma U373 cells upon down regulation of galectin-3 [69].

Galectin-3 was found to be over-expressed in TPA induced differentiation of the human promyelocytic leukemia cell line HL-60 to macrophages [70]. It potentiates lipopolysaccharide (LPS)-induced production of interleukin-1 (IL-1) [71] and triggers the production of superoxide anion by human peripheral blood monocytes [72] and neutrophils [73]. Presence of galectin-3 could induce a respiratory burst in human peripheral blood neutrophils after LPS exposure [74] paralleled by an increased binding of galectin-3 to the surface of the cells, possibly through functional receptors of galectin-3 in neutrophils CD66a and CD66b [75]. It was recently shown that galectin-3 increases phagocytic activity and CD66 surface expression on human neutrophils [76]. The exposure of human Jurkat $\mathrm{T}$ cells to galectin-3 stimulates the production of IL-2 [77], and it also acts as a mediator of IgE production in B lymphocytes in atopic eczema/dermatitis syndrome [78]. Galectin-3 was shown to activate cardiac fibroblasts [79] and was increased in synovial fibroblasts from rheumatoid arthritis patients after adhesion to cartilage oligomeric matrix protein [80].

Galectin-3 was also shown to cross link Mgat5-modified $\mathrm{N}$-glycans on EGF and TGF- $\beta$, and delaying their removal by constitutive endocytosis. It was speculated that the presence of extra-cellular galectin-3 can be a determining factor for prolonged cell activation [81]. On the other hand, the extra-cellular galectin-3 can act as a suppressor of cell activation as suggested by findings that galectin-3 crosslinking of Mgat5-modified $\mathrm{N}$ glycans on $\mathrm{T}$ cell receptors (TCR) prevents uncontrolled activation of $\mathrm{T}$ cells [82].

\section{Regulation of Apoptosis by Extracellular Galectin-3}

In the last decade, the role of galectin-3 as an anti-apoptotic molecule has been well established. It imparts resistance in response to various apoptotic insults in a wide variety of cells. Over-expression of galectin-3 in the human breast carcinoma cell line BT-549, resulted in reduced apoptotic death induced by cis-diamminedichloroplatinum (cisplatin), nitric oxide, radiation and anoikis compared to the parental or the control transfected cells $[9,83]$. Galectin-3 transfected Jurkat cells ( $\mathrm{T}$ lymphoma cell) were found to be more resistant to apoptosis induced by anti-Fas antibodies or staurosporine (protein kinase inhibitor) compared to the non-transfected control cells $[84,85]$. Galectin-3 is not a member of the $B c l-2$ gene family, however, it shares several significant structural properties with $B c l-2$. Both proteins are rich in proline, glycine, and alanine amino acid residues in the N-terminal domain and contain the Asp-Trp-Gly-Arg (NWGR) motif in the C-terminal domain [85, 86]. This motif, designated as the anti-death motif, is found in the BH-1 domain of $B c l-2$ and is shown to be critical for the anti-apoptotic function of this protein [87]. Even though endogenously expressed galectin-3 induced resistance to apoptosis, there is no experimental evidence to indicate that addition of galectin-3 exogenously induces apoptosis resistance in tumor cell lines of epithelial origin. However, it was reported recently that extra-cellular galectin-3 can induce apoptosis in human $\mathrm{T}$ cells including human peripheral blood mononuclear cells (PBMCs) and activated mouse T-cells [88]. This would imply that tumor cells secrete galectin-3 as a defense against infiltrating T-cells to enable them to survive and proliferate. Interestingly, the apoptotic sensitivity to galectin-3 varied among the different cell types of T-cell lymphoma cell lines. Based on the receptor type, two major signaling pathways have been reported for extrinsic apoptotic signals; one using the death receptors Fas (apo-1/CD95) and the other using TRAIL (TNF related apoptosis inducing ligand or Apo2-L) [89, 90]. Fas are glycosylated type- 1 transmembrane receptors that activate either mitochondria dependent or independent signaling pathways in the $\mathrm{T}$ cells in response to ligand, depending on the amount of active caspase- 8 produced at the death-inducing signaling complex (DISC) [91-94]. Analysis of two kinds of $\mathrm{T}$ cell lymphoma cell lines exhibiting either mitochondia independent (type I) and mitochondria dependent (type II) pathways showed that major difference between them is the presence of endogenous galectin-3. Galectin-3 was reported to be a binding partner of CD95 and galectin-3-null type I T-cell lines like Jurkat, CEM, and MOLT-4 cells that were significantly more sensitive to apoptosis by exogenous galectin- 3 than the type II cells SKW6.4 and H9, which have very high expression of endogenous galectin-3 [95]. It was suggested that there may be a cross talk between the anti-apoptotic activity of endogenous and pro-apoptotic activity of exogenous galectin-3 and the apoptotic effect may be caused from a balance between the two. In addition, when 
galectin-3 was over-expressed in type II CEM cells, there was binding of galectin-3 to CD95 receptor and the cells displayed type 1 signaling pathways [95].

There is no report on the effect of exogenously added galectin-3 on TRAIL induced apoptotic pathways in T cells, but galectin-3 over-expressing BT-549 breast cancer cells showed dephosphorylation of Akt in response to TRAIL-induced cytotoxicity [96] through regulation of phosphatase and tensin homologue deleted on chromosome 10 (PTEN) [97].

The galectin-3-sensitive T-cells Jurkat and CEM, both express CD29 and CD7 on the cell surface, whereas galectin3-insensitive cells like SKW6.4 and H9 express CD29 but not CD7. Extracellular galectin-3 can bind to the CD29/CD7 complex, which triggers the activation of intracellular apoptotic signaling toward the mitochondria inducing cytochrome c release and caspase 3 activation [88].

Extracellular galectin-3 can also bind to the T-cell receptor complex (TCR) through the polylactosamine structure extended by $N$-acetylglucosaminyltransferase $\mathrm{V}$ (GnT-V) and form clustering followed by down-regulation of T-cell activity [82]. In addition, CD98, which is implicated in the regulation of cell adhesion, growth and apoptosis, is a galectin-3 binding partner found on the surface of T-cells [53]. These results indicate that extra-cellular galectin-3 might not be an anti-apoptotic molecule by itself, but there is the possibility that its interaction with a glycoconjugate binding partner on the cell surface could protect cell viability and anti-apoptotic activity in some cells.

\section{Regulation of Angiogenesis and Tumor Progression by Galectin-3}

It was reported that secreted galectin-3 can induce endothelial cell morphogenesis in vitro and angiogenesis in vivo [54]. Binding of galectin-3 to the endothelial cell surface is dependent on its carbohydrate recognition domain as binding is specifically inhibited by a competitive disaccharide lactose and polysaccharide modified citrus pectin (MCP) [60]. In addition, the induction of endothelial cell motility and multicellular network formation in vitro and the stimulation of corneal angiogenesis in vivo provoked by NG2, a transmembrane chondroitin sulfate proteoglycan, was shown to be mediated by formation of NG2-galectin$3-\alpha 3 \beta 1$ integrin complex, suggesting a mechanism by which galectin-3 may induce angiogenesis [62]. Using a three-dimensional co-culture system of in vitro angiogenesis Shekhar et al. [10] demonstrated that galectin-3 is important for the stabilization of the epithelial and endothelial interactive network, as immuno-neutralization with anti-galectin-3 antibodies abolished these interactions. Over-expression of galectin-3 in transfected clones of LNCaP, a galectin-3-negative human prostate cancer cell line, induced in vivo tumor growth and angiogenesis [13]. Inhibitory studies were used to demonstrate significance of galectin-3 during angiogenesis. Three novel low molecular weight synthetic lactulose amines (SLA): $N$-lactulose-octamethylenediamine (LDO), $N, N^{\prime}$-dilactulose-octamethylenediamine (D-LDO), and $N, N^{\prime}$-dilactulose-dodecamethylene diamine (D-LDD) exhibiting differential ability to inhibit binding of galectin-3 to the highly glycosylated protein $90 \mathrm{~K}$, demonstrated selective regulatory effect in different events linked to endothelial cell morphogenesis and angiogenesis [98]. In addition, oral supplementation of modified citrus pectin, a high $\mathrm{pH}$ and temperature modified hydrolysis product of citrus pectin to nude mice showed reduced metastatic and angiogenic potential in breast cancer cells MDA-MB-435 [60].

\section{Cleavage of Galectin-3 by MMPs In Vitro and In Vivo}

Galectin-3 has a unique chimeric structure containing a domain of Pro-Gly-Tyr tandem repeats of $\sim 110$ amino acids which connects the $\mathrm{N}$-terminal to the $\mathrm{C}$ terminal. This $\alpha$ collagen-like domain is susceptible to cleavage by matrix metalloproteinases. Exhaustive bacterial collagenase degradation of both the murine and human recombinant homologues of galectin-3 generated a carboxy-terminal polypeptide capable of maintaining the sugar-binding properties of the cleaved molecule [27, 99-101]. Cleavage of human recombinant galectin-3 by human MMPs was first reported by Ochieng et al. [102], the cleavage site was identified at the $\mathrm{Ala}^{62}-\mathrm{Tyr}^{63}$ bond resulting in a $\sim 22$ and a $\sim 9 \mathrm{kDa}$ product. These authors also showed that after incubation with APMA activated MMP-2, cell surface expression of galectin-3 was reduced indicating that cell surface galectin-3 may also be cleaved by MMPs [102]. It was later demonstrated that the $\sim 22 \mathrm{kDa}$ cleaved product lacks the capacity to hemagglutinate fixed red blood cells and has reduced capacity to self-associate compared to the intact galectin-3 [100]. In addition, cleavage of galectin-3 by metalloproteinases drastically improves its binding interactions to laminin [100] and to endothelial cells (HUVEC) [10]. It was postulated that cleavage of galectin-3 by metalloproteinases results in an alteration of the CRD culminating in higher affinity to glycans and reducing the self association of the molecule thereby abrogating the biological properties dependent on such associations or homodimerization [100]. Shekhar et al. [10] detected additional bands of $\sim 27$ and $\sim 22 \mathrm{kDa}$ in the conditioned medium from the three-dimensional co-cultures of endothelial and epithelial cells. These co-cultures also showed extensive collagenolytic activity. Their results indicated that MMPs may cleave galectin-3 in the extracellular milieu. It has been well established that MMPs are synthesized as 
inactive proenzymes, which are activated by proteolytic cleavage of the propeptide domain after secretion [103]. The surface [102] or secreted [10] galectin-3 could be cleaved by extracellular MMPs. In another study by John et al. [104] treatment with a NH2 terminally truncated form of galectin-3 showed reduced tumor growth and metastasis of MDA-MB-435 cells compared with the control group. These authors concluded that truncated protein effectively competes with intracellular and extracellular galectin-3 and inhibits its hemophilic cross-linking and other types of protein-protein interactions. To analyze the biological significance of galectin-3 cleavage by MMPs, mutations were constructed at and around the MMP cleavage site $\mathrm{Ala}^{62}-\mathrm{Tyr}^{63}$. The results showed that $\mathrm{A}$ to $\mathrm{C}$ mutation at position 191 leading to substitution of $\mathrm{His}^{64}$ with Pro confers resistance to cleavage by MMP-2 and -9 at that position. Both the galectin-3 variants $\left(\mathrm{H}^{64}\right.$ and $\left.\mathrm{P}^{64}\right)$ were stably expressed in the galectin-3 null breast cancer cell line BT-549. The cells harboring a $\mathrm{P}^{64}$ variant showed an altered morphology, reduced chemotaxis and chemo-invasion, abrogated resistance to apoptosis, reduced tumor forming potential and angiogenesis (the functions regulated by extracellular galectin-3) as compared to the $\mathrm{H}^{64}$ galectin-3 harboring cells. On the other hand, the functions regulated by intracellular galectin-3, like cell proliferation and anchorage independent growth efficiency remained unchanged [105]. These results suggested that the extra-cellular cleavage of secreted galectin- $3 \mathrm{H}^{64}$ by MMPs may play a significant role during tumor development/progression. To analyze if this cleavage could also be observed in vivo, tissue array consisting of the progressive stages of breast cancer was stained with galectin3 monoclonal and polyclonal antibodies to selectively differentiate between the intact and cleaved galectin- 3 . The results showed that in the normal breast ducts no cleavage could be observed. In lobular hyperplasia the intact protein could be detected on the lobular side of the ducts, whereas the cleaved protein could be detected adjacent to the stroma. In ductal carcinoma in situ (DCIS), the full-length protein could be detected in a few epithelial cells, while the cleaved protein could be seen in the stroma. In the infilterating carcinomas, the invasive cell clusters and the surrounding stroma were positive for cleaved protein indicating that cleavage of galectin-3 is vital for the progression of breast cancer (unpublished data). A mouse model of human DCIS of the breast was utilized in order to analyze whether these results could be translated as a diagnostic tool to identify the activity of MMPs in vivo. Part of the xenograft was fresh frozen to perform in situ zymography, while the other part was paraffinembedded and stained with galectin-3 monoclonal and polyclonal antibodies. The results show an overlap between the MMP activities by in situ zymography and the cleavage of galectin-3 indicating that this differential staining could indeed be used as a surrogate diagnostic marker for MMP activity in the developing breast tumor [105].
Fig. 1 Extracellular functions mediated by galectin- 3 . The secreted galectin- 3 potentiates angiogenesis by facilitating migration, chemotaxis and morphogenesis of endothelial cells. It also induces $\mathrm{T}$ cell apoptosis. The cell surface protein is involved with homotypic and heterotypic cell aggregation and invasion leading to metastasis. Extracellular galectin-3 cross-links cell surface glycol-conjugates, form dimers and multimers, and delivers signals inside the cell. The $\sim 22 \mathrm{kDa}$ fragment of MMP cleaved galectin-3 binds to the glycan receptors more efficiently than the intact protein, the functions of smaller fragments are as yet unknown

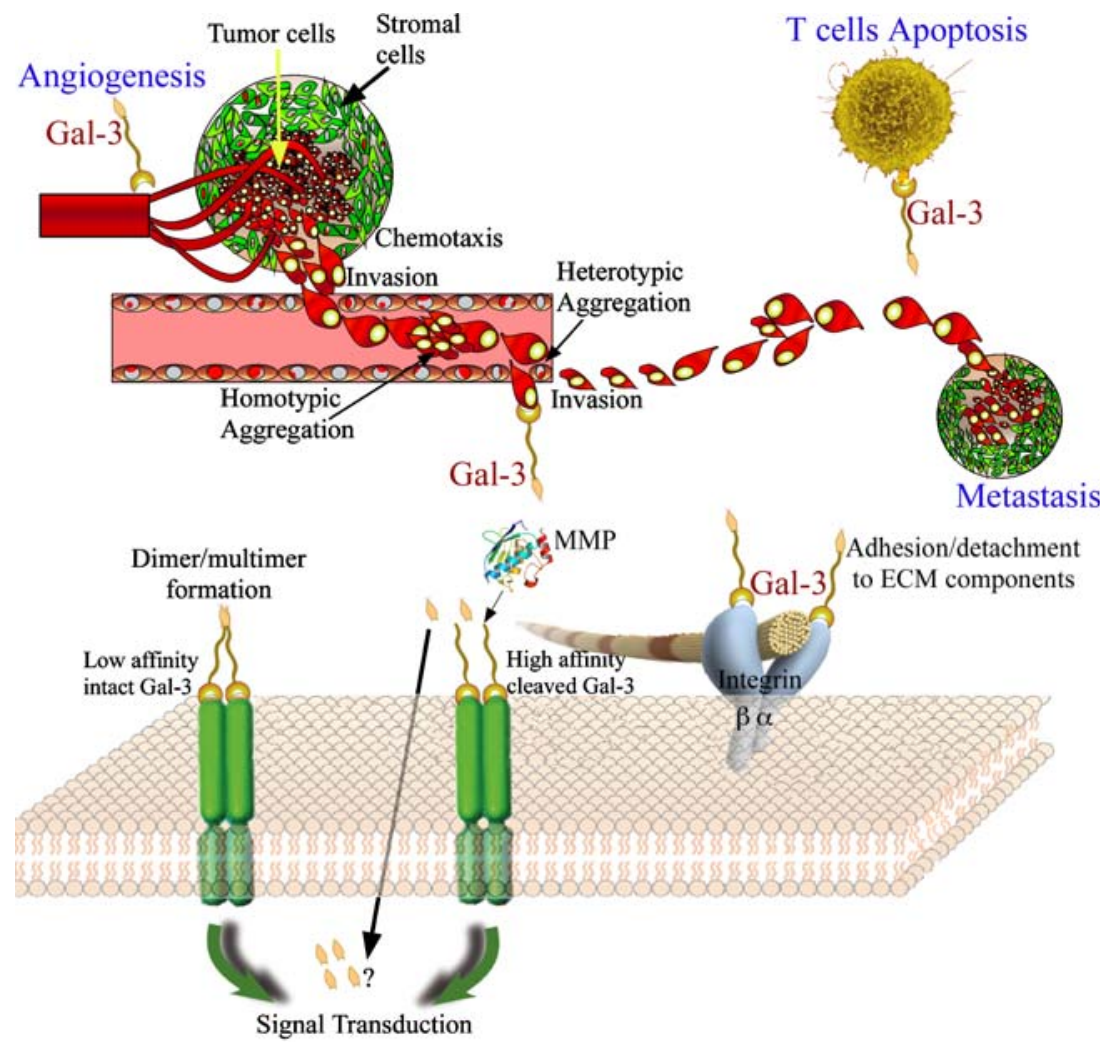




\section{Concluding Remarks}

Galectin-3 contributes to tumor progression through many different mechanisms. The biological roles of galectin-3 were initially attributed to its carbohydrate-binding activity. It was thought to play a role largely in cell adhesion leading to homotypic aggregation of tumor cell embolus in the blood circulation. During the past decade a whole new spectrum of its functions, unrelated to lectin activity, has been revealed and a plethora of physiological functions in the extracellular compartment have been assigned to it and more are yet to be discovered. Extracellular galectin-3 was found to be involved with cell-cell and cell-matrix adhesions, chemotaxis, chemoinvasion, apoptosis of the immune cells, angiogenesis and metastasis (Fig. 1). An under explored function of the extracellular galectin-3 is its cleavage by MMPs, which seems to play an important role in tumor progression. Cells harboring cleavage resistant galectin-3 showed reduced tumor growth, angiogenesis and resistance to apoptosis compared to the cleavage sensitive galectin-3. Cleavage of galectin-3 was observed increasingly with the progressive stages of breast cancer emphasizing its significance during tumor progression. It is yet to be established whether cleaved galectin-3 fragments follow the same signaling pathways as the full-length galectin-3. It was demonstrated that the larger $22 \mathrm{kDa}$ fragment retained its carbohydrate-binding properties, albeit it binds to the glycan receptors with a higher efficiency. The fate of the smaller fragments is as yet unknown. Whether they bind to the same receptors as the full-length protein or different ones; whether they are internalized by the cells or remain in the extracellular matrix and modulate the signaling pathways; what are the signaling pathways regulated by these fragments are some of the questions that still need to be answered.

Although the exact role of the galectin-3 cleavage in tumor progression is yet to be determined, its clinical significance as a surrogate diagnostic marker for the activity of MMPs in the tissues has been proposed. It is expected that identification and analysis of galectin-3 cleavage in cancer can be used as a tool for validation of the effectiveness of MMP inhibitor therapy.

Acknowledgements This work was supported by NIH R37CA4612019 (A. Raz). The authors would like to thank Victor Hogan and Tirza Raz for editing the manuscript.

\section{References}

1. Dumic J, Dabelic S, Flogel M (2006) Galectin-3: an open-ended story. Biochim Biophys Acta 1760:616-635

2. Van den Brule FA, Fernandez PL, Buicu C et al (1997) Differential expression of galectin-1 and galectin-3 during first trimester human embryogenesis. Dev Dyn 209:399-405
3. Fowlis D, Colnot C, Ripoche MA et al (1995) Galectin-3 is expressed in the notochord, developing bones, and skin of the postimplantation mouse embryo. Dev Dyn 203:241-251

4. Davidson PJ, Li SY, Lohse AG et al (2006) Transport of galectin-3 between the nucleus and cytoplasm. I. Conditions and signals for nuclear import. Glycobiology 16:602-611

5. Li SY, Davidson PJ, Lin NY et al (2006) Transport of galectin-3 between the nucleus and cytoplasm. II. Identification of the signal for nuclear export. Glycobiology 16:612-622

6. Davidson PJ, Davis MJ, Patterson RJ et al (2002) Shuttling of galectin-3 between the nucleus and cytoplasm. Glycobiology 12:329-337

7. van den Brule FA, Waltregny D, Liu FT et al (2000) Alteration of the cytoplasmic/nuclear expression pattern of galectin-3 correlates with prostate carcinoma progression. Int J Cancer 89:361-367

8. Yoshii T, Fukumori T, Honjo Y et al (2002) Galectin-3 phosphorylation is required for its anti-apoptotic function and cell cycle arrest. J Biol Chem 277:6852-6857

9. Yu F, Finley RL Jr., Raz A et al (2002) Galectin-3 translocates to the perinuclear membranes and inhibits cytochrome c release from the mitochondria. A role for synexin in galectin-3 translocation. J Biol Chem 277:15819-15827

10. Shekhar MP, Nangia-Makker P, Tait L et al (2004) Alterations in galectin-3 expression and distribution correlate with breast cancer progression: functional analysis of galectin-3 in breast epithelial-endothelial interactions. Am J Pathol 165:1931-1941

11. Moisa A, Fritz P, Eck A et al (2007) Growth/adhesion-regulatory tissue lectin galectin-3: stromal presence but not cytoplasmic/ nuclear expression in tumor cells as a negative prognostic factor in breast cancer. Anticancer Res 27:2131-2139

12. Sanjuan X, Fernandez PL, Castells A et al (1997) Differential expression of galectin 3 and galectin 1 in colorectal cancer progression [see comments]. Gastroenterology 113:1906-1915

13. Califice S, Castronovo V, Van Den Brule F (2004) Galectin-3 and cancer (Review). Int J Oncol 25:983-992

14. Honjo Y, Inohara H, Akahani S et al (2000) Expression of cytoplasmic galectin-3 as a prognostic marker in tongue carcinoma. Clin Cancer Res 6:4635-4640

15. Hughes RC (1999) Secretion of the galectin family of mammalian carbohydrate-binding proteins. Biochim Biophys Acta 1473:172-185

16. Nickel W (2005) Unconventional secretory routes: direct protein export across the plasma membrane of mammalian cells. Traffic 6:607-614

17. Gong HC, Honjo Y, Nangia-Makker P et al (1999) The NH2 terminus of galectin-3 governs cellular compartmentalization and functions in cancer cells. Cancer Res 59:6239-6245

18. Lukyanov P, Furtak V, Ochieng J (2005) Galectin-3 interacts with membrane lipids and penetrates the lipid bilayer. Biochem Biophys Res Commun 338:1031-1036

19. Sato S, Hughes RC (1994) Control of Mac-2 surface expression on murine macrophage cell lines. Eur J Immunol 24:216-221

20. Lindstedt R, Apodaca G, Barondes SH et al (1993) Apical secretion of a cytosolic protein by Madin-Darby canine kidney cells. Evidence for polarized release of an endogenous lectin by a nonclassical secretory pathway. J Biol Chem 268:11750-11757

21. Sato S, Burdett I, Hughes RC (1993) Secretion of the baby hamster kidney $30-\mathrm{kDa}$ galactose-binding lectin from polarized and nonpolarized cells: a pathway independent of the endoplasmic reticulum-Golgi complex. Exp Cell Res 207:8-18

22. Mehul B, Hughes RC (1997) Plasma membrane targeting, vesicular budding and release of galectin 3 from the cytoplasm of mammalian cells during secretion. J Cell Sci 110 (Pt 10):1169-1178

23. Sato S, Hughes RC (1994) Regulation of secretion and surface expression of Mac-2, a galactoside-binding protein of macrophages. J Biol Chem 269:4424-4430 
24. Thery C, Boussac M, Veron P et al (2001) Proteomic analysis of dendritic cell-derived exosomes: a secreted subcellular compartment distinct from apoptotic vesicles. J Immunol 166:7309-7318

25. Baptiste TA, James A, Saria M et al (2007) Mechano-transduction mediated secretion and uptake of galectin-3 in breast carcinoma cells: implications in the extracellular functions of the lectin. Exp Cell Res 313:652-664

26. Zhu WQ, Ochieng J (2001) Rapid release of intracellular galectin-3 from breast carcinoma cells by fetuin. Cancer Res 61:1869-1873

27. Agrwal N, Sun Q, Wang SY et al (1993) Carbohydrate-binding protein 35. I. Properties of the recombinant polypeptide and the individuality of the domains. J Biol Chem 268:14932-14939

28. Umemoto K, Leffler H, Venot A et al (2003) Conformational differences in liganded and unliganded states of galectin-3. Biochemistry 42:3688-3695

29. Mazurek N, Conklin J, Byrd JC et al (2000) Phosphorylation of the beta-galactoside-binding protein galectin-3 modulates binding to its ligands. J Biol Chem 275:36311-36315

30. Kuwabara I, Liu FT (1996) Galectin-3 promotes adhesion of human neutrophils to laminin. J Immunol 156:3939-3944

31. van den Brule FA, Buicu C, Sobel ME et al (1995) Galectin-3, a laminin binding protein, fails to modulate adhesion of human melanoma cells to laminin. Neoplasma 42:215-219

32. Sato S, Hughes RC (1992) Binding specificity of a baby hamster kidney lectin for H type I and II chains, polylactosamine glycans, and appropriately glycosylated forms of laminin and fibronectin. J Biol Chem 267:6983-6990

33. Hikita C, Vijayakumar S, Takito J et al (2000) Induction of terminal differentiation in epithelial cells requires polymerization of hensin by galectin 3. J Cell Biol 151:1235-1246

34. Ochieng J, Warfield P, Green-Jarvis B et al (1999) Galectin-3 regulates the adhesive interaction between breast carcinoma cells and elastin. J Cell Biochem 75:505-514

35. Probstmeier R, Montag D, Schachner M (1995) Galectin-3, a beta-galactoside-binding animal lectin, binds to neural recognition molecules. J Neurochem 64:2465-2472

36. Ochieng J, Leite-Browning ML, Warfield P (1998) Regulation of cellular adhesion to extracellular matrix proteins by galectin-3. Biochem Biophys Res Commun 246:788-791

37. Matarrese P, Fusco O, Tinari N et al (2000) Galectin-3 overexpression protects from apoptosis by improving cell adhesion properties. Int $\mathrm{J}$ Cancer 85:545-554

38. Raz A, Zhu DG, Hogan V et al (1990) Evidence for the role of 34-kDa galactoside-binding lectin in transformation and metastasis. Int J Cancer 46:871-877

39. Dong S, Hughes RC (1997) Macrophage surface glycoproteins binding to galectin-3 (Mac-2-antigen). Glycoconj J 14:267274

40. Ohannesian DW, Lotan D, Thomas P et al (1995) Carcinoembryonic antigen and other glycoconjugates act as ligands for galectin-3 in human colon carcinoma cells. Cancer Res 55:21912199

41. Bresalier RS, Byrd JC, Wang L et al (1996) Colon cancer mucin: a new ligand for the beta-galactoside-binding protein galectin-3. Cancer Res 56:4354-4357

42. Warfield PR, Makker PN, Raz A et al (1997) Adhesion of human breast carcinoma to extracellular matrix proteins is modulated by galectin-3. Invasion Metastasis 17:101-112

43. Furtak V, Hatcher F, Ochieng J (2001) Galectin-3 mediates the endocytosis of beta- 1 integrins by breast carcinoma cells. Biochem Biophys Res Commun 289:845-850

44. Ochieng J, Gerold M, Raz A (1992) Dichotomy in the lamininbinding properties of soluble and membrane-bound human galactoside-binding protein. Biochem Biophys Res Commun $186: 1674-1680$
45. Woo HJ, Lotz MM, Jung JU et al (1991) Carbohydrate-binding protein 35 (Mac-2), a laminin-binding lectin, forms functional dimers using cysteine 186. J Biol Chem 266:18419-18422

46. Knibbs RN, Agrwal N, Wang JL et al (1993) Carbohydratebinding protein 35. II. Analysis of the interaction of the recombinant polypeptide with saccharides. J Biol Chem 268:14940-14947

47. Yang RY, Hill PN, Hsu DK et al (1998) Role of the carboxylterminal lectin domain in self-association of galectin-3. Biochemistry 37:4086-4092

48. Ahmad N, Gabius HJ, Andre S et al (2004) Galectin-3 precipitates as a pentamer with synthetic multivalent carbohydrates and forms heterogeneous cross-linked complexes. J Biol Chem 279:10841-10847

49. Inohara $\mathrm{H}$, Akahani $\mathrm{S}$, Koths $\mathrm{K}$ et al (1996) Interactions between galectin-3 and Mac-2-binding protein mediate cell-cell adhesion. Cancer Res 56:4530-4534

50. Glinsky VV, Glinsky GV, Rittenhouse-Olson K et al (2001) The role of Thomsen-Friedenreich antigen in adhesion of human breast and prostate cancer cells to the endothelium. Cancer Res 61:4851-4857

51. Glinsky VV, Huflejt ME, Glinsky GV et al (2000) Effects of Thomsen-Friedenreich antigen-specific peptide P-30 on betagalactoside-mediated homotypic aggregation and adhesion to the endothelium of MDA-MB-435 human breast carcinoma cells. Cancer Res 60:2584-2588

52. Grassadonia A, Tinari N, Iurisci I et al (2004) 90K (Mac-2 BP) and galectins in tumor progression and metastasis. Glycoconj $\mathrm{J}$ 19:551-556

53. Hughes RC (2001) Galectins as modulators of cell adhesion. Biochimie 83:667-676

54. Nangia-Makker P, Honjo Y, Sarvis R et al (2000) Galectin-3 induces endothelial cell morphogenesis and angiogenesis. Am J Pathol 156:899-909

55. Lehr JE, Pienta KJ (1998) Preferential adhesion of prostate cancer cells to a human bone marrow endothelial cell line [see comments]. J Natl Cancer Inst 90:118-123

56. Khaldoyanidi SK, Glinsky VV, Sikora L et al (2003) MDA-MB435 human breast carcinoma cell homo- and heterotypic adhesion under flow conditions is mediated in part by Thomsen-Friedenreich antigen-galectin-3 interactions. J Biol Chem 278:4127-4134

57. Gil CD, La M, Perretti $M$ et al (2006) Interaction of human neutrophils with endothelial cells regulates the expression of endogenous proteins annexin 1, galectin-1 and galectin-3. Cell Biol Int 30:338-344

58. Krishnan V, Bane SM, Kawle PD et al (2005) Altered melanoma cell surface glycosylation mediates organ specific adhesion and metastasis via lectin receptors on the lung vascular endothelium. Clin Exp Metastasis 22:11-24

59. Inohara H, Raz A (1994) Effects of natural complex carbohydrate (citrus pectin) on murine melanoma cell properties related to galectin-3 functions. Glycoconj J 11:527-532

60. Nangia-Makker P, Hogan V, Honjo Y et al (2002) Inhibition of human cancer cell growth and metastasis in nude mice by oral intake of modified citrus pectin. J Natl Cancer Inst 94:1854-1862

61. Zou J, Glinsky VV, Landon LA et al (2005) Peptides specific to the galectin-3 carbohydrate recognition domain inhibit metastasisassociated cancer cell adhesion. Carcinogenesis 26: 309-318

62. Fukushi J, Makagiansar IT, Stallcup WB (2004) NG2 proteoglycan promotes endothelial cell motility and angiogenesis via engagement of galectin-3 and alpha3beta1 integrin. Mol Biol Cell 15:3580-3590

63. Sano H, Hsu DK, Yu L et al (2000) Human galectin-3 is a novel chemoattractant for monocytes and macrophages. J Immunol $165: 2156-2164$ 
64. Camby I, Belot N, Rorive S et al (2001) Galectins are differentially expressed in supratentorial pilocytic astrocytomas, astrocytomas, anaplastic astrocytomas and glioblastomas, and significantly modulate tumor astrocyte migration. Brain Pathol 11:12-26

65. Savino W, Mendes-Da-Cruz DA, Smaniotto S et al (2004) Molecular mechanisms governing thymocyte migration: combined role of chemokines and extracellular matrix. J Leukoc Biol 75:951-961

66. O'Driscoll L, Linehan R, Liang YH et al (2002) Galectin-3 expression alters adhesion, motility and invasion in a lung cell line (DLKP), in vitro. Anticancer Res 22:3117-3125

67. Lagana A, Goetz JG, Cheung P et al (2006) Galectin binding to Mgat5-modified N-glycans regulates fibronectin matrix remodeling in tumor cells. Mol Cell Biol 26:3181-3193

68. Hittelet A, Camby I, Nagy N et al (2003) Binding sites for Lewis antigens are expressed by human colon cancer cells and negatively affect their migration. Lab Invest 83:777-787

69. Debray C, Vereecken P, Belot N et al (2004) Multifaceted role of galectin-3 on human glioblastoma cell motility. Biochem Biophys Res Commun 325:1393-1398

70. Nangia-Makker P, Ochieng J, Christman JK et al (1993) Regulation of the expression of galactoside-binding lectin during human monocytic differentiation. Cancer Res 53:5033-5037

71. Jeng KC, Frigeri LG, Liu FT (1994) An endogenous lectin, galectin-3 (epsilon BP/Mac-2), potentiates IL-1 production by human monocytes. Immunol Lett 42:113-116

72. Liu FT, Hsu DK, Zuberi RI et al (1995) Expression and function of galectin-3, a beta-galactoside-binding lectin, in human monocytes and macrophages. Am J Pathol 147:1016-1028

73. Yamaoka A, Kuwabara I, Frigeri LG et al (1995) A human lectin, galectin-3 (epsilon bp/Mac-2), stimulates superoxide production by neutrophils. J Immunol 154:3479-3487

74. Almkvist J, Faldt J, Dahlgren C et al (2001) Lipopolysaccharideinduced gelatinase granule mobilization primes neutrophils for activation by galectin-3 and formylmethionyl-Leu-Phe. Infect Immun 69:832-837

75. Feuk-Lagerstedt E, Jordan ET, Leffler H et al (1999) Identification of $\mathrm{CD} 66 \mathrm{a}$ and $\mathrm{CD} 66 \mathrm{~b}$ as the major galectin-3 receptor candidates in human neutrophils. J Immunol 163:5592-5598

76. Fernandez GC, Ilarregui JM, Rubel CJ et al (2005) Galectin-3 and soluble fibrinogen act in concert to modulate neutrophil activation and survival: involvement of alternative MAPK pathways. Glycobiology 15:519-527

77. Hsu DK, Hammes SR, Kuwabara I et al (1996) Human T lymphotropic virus-I infection of human $\mathrm{T}$ lymphocytes induces expression of the beta-galactoside-binding lectin, galectin-3. Am J Pathol 148:1661-1670

78. Kimata H (2002) Enhancement of IgE production in B cells by neutrophils via galectin-3 in IgE-associated atopic eczema/ dermatitis syndrome. Int Arch Allergy Immunol 128:168-170

79. Sharma UC, Pokharel S, van Brakel TJ et al (2004) Galectin-3 marks activated macrophages in failure-prone hypertrophied hearts and contributes to cardiac dysfunction. Circulation 110:3121-3128

80. Neidhart M, Zaucke F, von Knoch R et al (2005) Galectin-3 is induced in rheumatoid arthritis synovial fibroblasts after adhesion to cartilage oligomeric matrix protein. Ann Rheum Dis 64:419-424

81. Dennis JW, Pawling J, Cheung P et al (2002) UDP- $N$ acetylglucosamine:alpha-6-D-mannoside beta1,6 N-acetylglucosaminyltransferase V (Mgat5) deficient mice. Biochim Biophys Acta 1573:414-422

82. Demetriou M, Granovsky M, Quaggin S et al (2001) Negative regulation of T-cell activation and autoimmunity by Mgat5 Nglycosylation. Nature 409:733-739

83. Suliman A, Lam A, Datta R et al (2001) Intracellular mechanisms of TRAIL: apoptosis through mitochondrial-dependent and -independent pathways. Oncogene 20:2122-2133
84. Liu FT, Patterson RJ, Wang JL (2002) Intracellular functions of galectins. Biochim Biophys Acta 1572:263-273

85. Yang RY, Hsu DK, Liu FT (1996) Expression of galectin-3 modulates T-cell growth and apoptosis. Proc Natl Acad Sci U S A 93:6737-6742

86. Akahani S, Nangia-Makker P, Inohara H et al (1997) Galectin-3: a novel antiapoptotic molecule with a functional BH1 (NWGR) domain of Bcl-2 family. Cancer Res 57:5272-5276

87. Hanada M, Aime-Sempe C, Sato T et al (1995) Structurefunction analysis of Bcl-2 protein. Identification of conserved domains important for homodimerization with $\mathrm{Bcl}-2$ and heterodimerization with Bax. J Biol Chem 270:11962-11969

88. Fukumori T, Takenaka Y, Yoshii T et al (2003) CD29 and CD7 mediate galectin-3-induced type II T-cell apoptosis. Cancer Res 63:8302-8311

89. Ashkenazi A, Dixit VM (1998) Death receptors: signaling and modulation. Science 281:1305-1308

90. Schulze-Osthoff K, Ferrari D, Los M et al (1998) Apoptosis signaling by death receptors. Eur J Biochem 254:439-459

91. Scaffidi C, Fulda S, Srinivasan A et al (1998) Two CD95 (APO1/Fas) signaling pathways. Embo J 17:1675-1687

92. Nagata S (2000) Apoptotic DNA fragmentation. Exp Cell Res 256:12-18

93. Peter ME, Krammer PH (1998) Mechanisms of CD95 (APO-1/ Fas)-mediated apoptosis. Curr Opin Immunol 10:545-551

94. Peter ME, Krammer PH (2003) The CD95(APO-1/Fas) DISC and beyond. Cell Death Differ 10:26-35

95. Fukumori T, Takenaka Y, Oka N et al (2004) Endogenous galectin-3 determines the routing of CD95 apoptotic signaling pathways. Cancer Res 64:3376-3379

96. Lee YJ, Song YK, Song JJ et al (2003) Reconstitution of galectin-3 alters glutathione content and potentiates TRAIL-induced cytotoxicity by dephosphorylation of Akt. Exp Cell Res 288:21-34

97. Mazurek N, Sun YJ, Liu KF et al (2007) Phosphorylated galectin-3 mediates tumor necrosis factor-related apoptosisinducing ligand signaling by regulating phosphatase and tensin homologue deleted on chromosome 10 in human breast carcinoma cells. J Biol Chem 282:21337-21348

98. Rabinovich GA, Cumashi A, Bianco GA et al (2006) Synthetic lactulose amines: novel class of anticancer agents that induce tumorcell apoptosis and inhibit galectin-mediated homotypic cell aggregation and endothelial cell morphogenesis. Glycobiology 16:210-220

99. Hsu DK, Zuberi RI, Liu FT (1992) Biochemical and biophysical characterization of human recombinant IgE- binding protein, an S-type animal lectin. J Biol Chem 267:14167-14174

100. Ochieng J, Green B, Evans S et al (1998) Modulation of the biological functions of galectin- 3 by matrix metalloproteinases. Biochim Biophys Acta 1379:97-106

101. Raz A, Pazerini G, Carmi P (1989) Identification of the metastasis-associated, galactoside-binding lectin as a chimeric gene product with homology to an IgE-binding protein. Cancer Res 49:3489-3493

102. Ochieng J, Fridman R, Nangia-Makker P et al (1994) Galectin-3 is a novel substrate for human matrix metalloproteinases-2 and 9. Biochemistry 33:14109-14114

103. Nagase H, Woessner JF, Jr. (1999) Matrix metalloproteinases. J Biol Chem 274:21491-21494

104. John CM, Leffler H, Kahl-Knutsson B et al (2003) Truncated galectin-3 inhibits tumor growth and metastasis in orthotopic nude mouse model of human breast cancer. Clin Cancer Res 9:2374-2383

105. Nangia-Makker P, Raz T, Tait L, Hogan V, Fridman R, Raz A (2007) Galectin-3 cleavage: a novel surrogate marker for matrix metalloproteinase activity in growing breast cancer. Cancer Res 67:11760-11768 